bradycardias and tachycardias and good working practice guidelines issued. Efforts in better education continue and to this end a full day programme will be held on 17 October 1994 to provide an update on all aspects of tachycardias and bradycardias and their treatment. Further information on this meeting, to be held in London, can be obtained from the BPEG office at 9 Fitzroy Square, London W1P 5AH (tel: 071636 5994)."

British Society of Echocardiography Mark Monaghan writes: "The British Society of Echocardiography has been going through a very busy period. We had a highly successful session during the Torquay meeting. Two debates were held on controversial topics in echocardiography, which proved to be highly entertaining and lively. Undoubtedly, this is a formula that we shall repeat.

Plans are well under way for our Autumn meeting, to be held at the Bedford Hotel in Brighton on Friday 25 and Saturday 26 November 1994. The first day will consist of presentations of abstracts (the closing date for receipt of abstracts is 2 September 1994). These abstracts will be published in Echocardiography 1995-a supplement to the British Heart fournal. On Saturday 26 November there will be a series of more practically orientated lectures, covering topics such as the diagnosis of pericardial disease and aortic dissection. Surgeons, cardiologists, and echocardiographers are all contributing to these topics and we are anticipating another very lively meeting.

We plan to hold the first of our proficiency level assessments during our Autumn meeting. These will include multiple choice questions and video tapes, etc., for those candidates wishing to apply for BSE proficiency level accreditation. In addition, candidates will have to complete a log book of completed cases. However, the log book does not have to be finished before the assessment is taken.

We have made some representations to the British Cardiac Society about the guidelines for specialist training in cardiology. We are pleased to see echocardiography given appropriate prominence in these recommendations. However, we would like to find some common ground on recommended numbers of cases and assessments. No doubt, this will be an ongoing discussion.

As previously mentioned, preparation of the next edition of our supplement to the British Heart fournal is already well advanced. Various articles, which will all be peer reviewed, are being prepared in addition to the abstracts from our Autumn meeting.

Our new membership administrator has a new computer system and database which will allow us to deal with our membership records more efficiently and also to store information such as training accreditation.

We are also planning a joint meeting with BCIS on interventional ultrasound. This will cover topics such as valvuloplasty, intravascular ultrasound, Doppler flow wire, etc. More details of this meeting will follow.

Finally, we have moved our annual general meeting to coincide with our Autumn meeting. This avoids our taking up valuable time during the British Cardiac Society annual meeting".

\section{News from Europe}

Philip Poole-Wilson writes: "By the time this is being read, the Congress in Berlin will be over. The organisation of this Congress has been a particular challenge to the European Society of Cardiology because it is not only the XVIth Congress of the European Society of Cardiology but also the XIIth World Congress of Cardiology. World Congresses occur every four years and are the meetings of the International Society and Federation of Cardiology (ISFC). The current President is David Kelly from Sydney, Australia. In Berlin he will be succeeded by Eliot Rapport from the USA.

We must now look ahead to the Congress in Amsterdam on 20-24 August, 1995. The planning committee meets on 27 October 1995. If you have suggestions for the programme please pass them directly to ECOR, to the chairman of a working group or, if you wish, directly to me. I will act as postman. Abstracts need to be received by ECOR by 14 February 1995. Application forms can be obtained from ECOR. The address of ECOR is: European Heart House, 2035 route des Colles, Les Templiers-BP 179, 06093 Sophia Antipolis Cedex, France (tel: 0103392 947600; fax: 0103392 947601)."

\section{Forthcoming meetings}

The annual meeting of the British Nuclear Cardiology Group will be held on 12 December, 1994 at St Thomas' Hospital in London. The programme, which is based on the theme of "How we will assess reversible ischaemia in the year 2000 ", can be obtained from Dudley Pennell at the
Royal Brompton Hospital (tel: 071351 8810). Professor Mario Verani from Houston, Texas will be giving the keynote lecture.

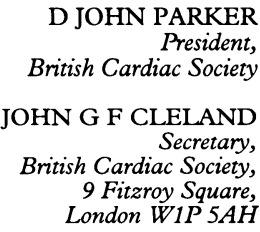

The 1995 Annual Meeting of the British Cardiac Society will take place at the Conference Centre, Harrogate, West Yorkshire from 23 to 25 May.

\section{CORRECTION}

Short-term effects of right atrial, right ventricular apical, and atrioventricular sequential pacing on myocardial oxygen consumption and cardiac efficiency in patients with coronary artery disease.

Z S Kyriakides, A Antoniadis, E Iliodromitis, N Michelakakis, D T Kremastinos (Br Heart f 1994;71:536-40). In the formula for myocardial oxygen consumption (p 537) the first variable was given as $\mathrm{CO}$ (cardiac output). It should have been myocardial blood flow. The correct formula is $\mathrm{MVO}_{2}=$ $\mathrm{MBF} \times$ (arterial $\mathrm{O}_{2}$ saturation - coronary sinus $\mathrm{O}_{2}$ saturation $\times \mathrm{Hb} \times 1.36\left(\mathrm{ml} \mathrm{O}_{2} / \mathrm{min}\right)$, where MBF is the myocardial blood flow in $\mathrm{l} / \mathrm{min}$ and $\mathrm{Hb}$ is haemoglobin in $\mathrm{g} / 100 \mathrm{ml}$. 